\title{
Anxiety and depression-like behaviours are more frequent in aged male mice conceived by ART compared with natural conception
}

\author{
Ning-Xin Qin ${ }^{4, *}$, Yi-Ran Zhao ${ }^{1,2, *}$, Wei-Hui Shi ${ }^{1,2, *}$, Zhi-Yang Zhou ${ }^{1,2}$, Ke-Xin Zou ${ }^{1,2}$, \\ Chuan-Jin Yu ${ }^{1,2}$, Xia Liu ${ }^{1,2}$, Ze-Han Dong ${ }^{1,2}$, Yi-Ting Mao ${ }^{1,2}$, Cheng-Liang Zhou ${ }^{1,2}$, Jia-Le Yu ${ }^{1,2}$, \\ Xin-Mei Liu ${ }^{3}$, Jian-Zhong Sheng ${ }^{5}$, Guo-Lian Ding ${ }^{3}$, Wen-Long Zhao ${ }^{1,2}$, Yan-Ting Wu ${ }^{3}$ and \\ He-Feng Huang ${ }^{1,2,3,6}$
}

${ }^{1}$ The International Peace Maternity and Child Health Hospital, School of Medicine, Shanghai Jiao Tong University, Shanghai, China, ${ }^{2}$ Shanghai Key Laboratory of Embryo Original Diseases, Shanghai, China, ${ }^{3}$ Hospital of Obstetrics and Gynecology, Fudan University, Shanghai, China, ${ }^{4}$ Department of Assisted Reproductive Medicine, Shanghai First Maternity and Infant Hospital, School of Medicine, Tongji University, Shanghai, China, ${ }^{5}$ Department of Pathology and Pathophysiology, Zhejiang University School of Medicine, Hangzhou, Zhejiang, China and ${ }^{6}$ The Key Laboratory of Reproductive Genetics (Zhejiang University), Ministry of Education, Zhejiang University School of Medicine, Hangzhou, Zhejiang, China

Correspondence should be addressed to W-L Zhao or Y-T Wu or H-F Huang; Email: zwlzby-09@163.com or yanting_wu@163. com or huanghefg@sjtu.edu.cn

*(N-X Qin, Y-R Zhao and W-H Shi contributed equally to this work)

\begin{abstract}
The number of children born after assisted reproductive technology (ART) is accumulating rapidly, and the health problems of the children are extensively concerned. This study aims to evaluate whether ART procedures alter behaviours in male offspring. Mouse models were utilized to establish three groups of offspring conceived by natural conception (NC), in vitro fertilization and embryo transfer (IVF-ET), and frozen-thawed embryo transfer (IVF-FET), respectively. A battery of behaviour experiments for evaluating anxiety and depression levels, including the open field test (OFT), elevated plus maze (EPM) test, light/dark transition test (L/DTT), tail suspension test (TST), forced swimming test (FST), and sucrose preference test (SPT) was carried out. Aged (18 months old), but not young (3 months old), male offspring in the IVF-ET and IVF-FET groups, compared with those in the NC group, exhibited increased anxiety and depression-like behaviours. The protein expression levels of three neurotrophins in PFC or hippocampus in aged male offspring from the IVF-ET and IVF-FET groups reduced at different extent, in comparison to NC group. RNA sequencing (RNA-Seq) was performed in the hippocampus of 18 months old offspring to further explore the gene expression profile changes in the three groups. KEGG analyses revealed the coexisted pathways, such as PI3K-Akt signalling pathway, which potentially reflected the similarity and divergence in anxiety and depression between the offspring conceived by IVF-ET and IVF-FET. Our research suggested the adverse effects of advanced age on the psychological health of children born after ART should be highlighted in the future.

Reproduction (2021) 162 437-448
\end{abstract}

\section{Introduction}

Assisted reproductive technology (ART), mainly including in vitro fertilization and embryo transfer (IVF-ET), frozen-thawed embryo transfer (FET), has been widely used for infertility treatment since the first baby was born from IVF-ET in 1978 (Steptoe \& Edwards 1978). The health problems of children born after ART are concerned extensively (Hart \& Norman 2013a,b, Turkgeldi et al. 2016, Berntsen et al. 2019). Previous studies have suggested adverse effects of ART on the offspring such as heightened risks of autism and intellectual disability, arterial hypertension, cancer, and metabolic dysfunctions during childhood and adolescence (Sandin et al. 2013, Meister et al. 2018, Hargreave et al. 2019, Cui et al. 2020). Furthermore, studies using ART mouse models have shown the potential risks of many diseases, especially glucose metabolism dysfunction and cardiovascular diseases, in the adult and aged offspring (Watkins et al. 2007, Scott et al. 2010, Chen et al. 2014, Donjacour et al. 2014, Schenewerk et al. 2014, Rexhaj et al. 2015, Cerny et al. 
2017, Wang et al. 2018, Zheng et al. 2018, Aljahdali et al. 2020). However, there are still limited studies focused on psychiatry on ART-conceived offspring.

In modern society, mental disorders are common problems concerned extensively (Barbeito et al. 2021). Anxiety and depression are among the most frequent mental disorders with an approximated prevalence of 7.3 and $4.7 \%$, respectively, ultimately leading to destroy social ability and work enthusiasm of patients, increase suicide rate in the population, and cause serious health and economic burden in the global population (Baxter et al. 2013, Ferrari et al. 2013). Timely diagnosis and prevention of anxiety and depression enable to reduce the medical cost and burden, slow down the development of the diseases, and improve the prognosis (Garber et al. 2016, Werner-Seidler et al. 2017, Faye et al. 2018, Salazar de Pablo et al. 2021). However, studies regarding anxiety and depression status for ART-conceived offspring are still lacking. Meantime, it is difficult to assess anxiety and depression in human beings conceived by ART in adulthood and old age, accounting for a short time span from the first application of the technologies. Due to the life span of mice is shorter than that of humans, the mouse model is an effective approach to assess the longterm effects on offspring conceived by ART (Vrooman \& Bartolomei 2017, Duranthon \& Chavatte-Palmer 2018, Sharpe 2018).

There are many classical methods to evaluate anxiety and depression levels in mouse (Pollak et al. 2010, Harro 2019, Himanshu et al. 2020, Moulin et al. 2021, Pentkowski et al. 2021). For example, the open field test (OFT), elevated plus maze (EPM), and light/ dark transition test (L/DTT) were carried out to assess the anxiety behaviours in the ART-conceived mice. The tail suspension test (TST), forced swimming test (FST), and sucrose preference test (SPT) were applied to assess depression behaviours. Basic locomotion was recorded in the OFT to assess mouse motility. As neuropsychiatric symptoms are always linked to cognition impairment, spatial learning and memory ability were evaluated using the Morris water maze (MWM) (Unal \& Canbeyli 2019). It is well known that sex bias between males and females was common in neuroethology. There were previous studies reported that fluctuating levels of gonadal steroids and inconsistent oestrous cycle among each female mouse would interfere with the accuracy of behavioural results (Carrier et al. 2015, Boivin et al. 2017, Oyola \& Handa 2017, Andreae \& Basson 2018, Datta et al. 2019, Gerhard et al. 2021, Mossa \& Manzini 2021). Secondly, loss of reproductive competence and alteration of hormone levels in old female mice are more apparent in old male mice at 18 months old. These physiological phenomena also exist in humans. These factors mentioned above suggest more confounders would be brought in our result if we evaluate the female offspring. Thus, we only performed behavioural tests in male offspring.
The hippocampus and prefrontal cortex (PFC) are two crucial brain regions strongly involved in anxiety and depression-like behaviours in rodents (Snyder et al. 2011, Kheirbek et al. 2012, Hiser \& Koenigs 2018, Hare \& Duman 2020). Decreased volume, neurogenesis, and altered neuronal apoptosis in the hippocampus have been implicated in the pathogenesis of anxiety and depression (Snyder et al. 2011, Kheirbek et al. 2012, Mineur et al. 2013). The PFC is a key node of cortical and subcortical networks that subserve psychological functions linked to psychopathology (Hiser \& Koenigs 2018). Brain-derived neurotrophic factor (BDNF), glial cell-derived neurotrophic factor (GDNF), and nerve growth factor (NGF) are three important neurotrophins involved in neurogenesis and pathophysiology of many nervous system diseases (Angelucci et al. 2004, Allen et al. 2013, de Azevedo Cardoso et al. 2014, Castren \& Monteggia 2021). The reduction of neurotrophins in the hippocampus and PFC was one of the major pathological features in anxiety and depression (Thoenen 1995, Autry \& Monteggia 2012, Kristiansen \& Ham 2014, Notaras et al. 2015, Ayanlaja et al. 2018, Koo et al. 2019). These three neurotrophins play essential roles in nervous system development and function by promoting nerve growth, neurological development, and neuronal plasticity (Thoenen 1995, Kalueff et al. 2006, Martinowich et al. 2007).

The aim of the study was to assess the anxiety and depression levels in ART-conceived male mice offspring in adulthood and old age. Importantly, ART-conceived male mice exhibited increased anxiety and depression behaviours in old age compared with offspring conceived by natural conception, rather than in adulthood. Decreased neurotrophin protein expression levels in the hippocampus and PFC of mice in the IVF-ET and IVF-FET groups, compared with NC group, were in concordance with the behavioural results.

\section{Materials and methods}

\section{Mouse model and experimental design}

All experimental procedures with mice were approved by the Shanghai Model Organisms Center ethical committee in animal research (IACUC approval number: 2019-0002). Virgin 6- to 8-week-old B6D2F1/J (C57B6L/J x DBA2/J) female mice, adult B6D2F1/J males, 8-week-old ICR females, and adult vasectomized ICR males were used. All animals were housed in the same room maintained under a constant $12 \mathrm{~h}$ light: 12 h darkness cycle at $21-23{ }^{\circ} \mathrm{C}$, with free access to food and water. The overall processes in this study were followed by the flowchart in Fig. 1. Mice offspring were divided into three groups according to the different approaches they conceived by (Fig. 1A). The natural conception (NC) group is comprised of male mice offspring conceived by natural mating and delivery. Pseudo-pregnant females ICR mice were obtained by mating with vasectomized male mice. Fresh two-cell embryos or embryos after cryopreservation in the liquid nitrogen for 1 


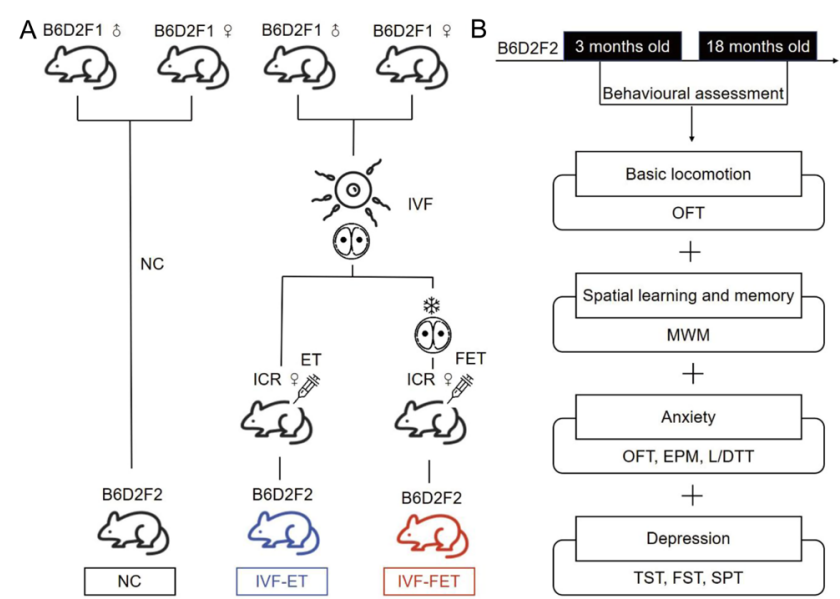

Figure 1 Experimental design. (A) The male mice offspring were divided into NC, IVF-ET, and IVF-FET groups. (B) Behavioural experiments were performed in the male mice offspring at 3 and 18 months old.

week and thawed for $2 \mathrm{~h}$ were transferred to pseudo-pregnant mice. The offspring born after IVF-ET or IVF-FET were referred as to IVF-ET group and IVF-FET group, respectively. Two-cell embryos in IVF-ET and IVF-FET groups were obtained by standard B6D2F1 × B6D2F1 IVF. The IVF, embryo transfer, embryo frozen, and thawed procedures have been described previously (Qin et al. 2021). The offspring were weaned and separated by sex until postnatal day 20 .

\section{Behavioural assessments}

All behavioural assays were performed when the offspring were 3 and 18 months old ( $n=7$ male offspring/group/age, Fig. 1B). Behavioural tests were recorded by Ethovision XT 13 software (Noldus Information Technology, Netherlands) from 9:00 to 16:00 h, and data were analysed in a blinded manner. Mice were handled for 3 days and habituated to the testing room for $30 \mathrm{~min}$ before performing the behavioural experiments. The apparatuses were cleaned with $70 \%$ ethanol and water between trials in all experiments.

\section{Open field test (OFT)}

The OFT experiment was widely used to assess basic locomotion and anxiety behaviours in rodents (Prut \& Belzung 2003). The OFT was conducted using a chamber $(40 \mathrm{~cm} \times 40$ $\mathrm{cm}$ ) to determine the general locomotor activity of mice. After placing each mouse in the same corner into the chamber, the behaviour of the mouse was recorded by a camera for $15 \mathrm{~min}$. The centre zone was defined as $20 \mathrm{~cm} \times 20 \mathrm{~cm}$. The total distance, the entry times in the centre zone, the distance, and time spent in the centre zone were indicated the locomotor activity and anxiety level of mice.

\section{Morris water maze (MWM)}

Spatial learning and memory abilities were assessed by MWM (Puzzo et al. 2014). It is mainly composed of a circular pool with a diameter of $1.6 \mathrm{~m}$ and a height of $0.6 \mathrm{~m}$, filled with $0.4 \mathrm{~m}$ of $18-26^{\circ} \mathrm{C}$ water. The training and test procedures were carried out as previously described (Brandeis et al. 1989). The quadrant with platform was termed as the 'target quadrant'. The latency to platform hidden under water and the distance in the target quadrant were recorded.

\section{Elevated plus maze (EPM) test}

The EPM was performed to assess anxiety behaviours in the offspring (Walf \& Frye 2007). Mice were placed in the centre area of an EPM (arms are $35 \times 7 \mathrm{~cm}$, with $150 \mathrm{~mm}$-high black walls on the closed arms), and the trajectories of mice were recorded with a video camera for $5 \mathrm{~min}$. The total distance travelled and the distance, entry times, and time spent in the open arms were automatically quantified by the tracking software.

\section{Light/dark transition test (L/DTT)}

The L/DTT was performed to assess anxiety level in the offspring, as previously reported (Crawley \& Goodwin 1980). Briefly, the apparatus for L/DTT was a two-compartment box $(210 \times 420 \times 250 \mathrm{~mm})$ through a small door. One chamber was brightly illuminated (300 lx, bright chamber), while the other chamber had black plastic walls and was dark (2 Ix). The mouse was placed in the dark compartment and given free access to the light compartment for $10 \mathrm{~min}$. The distance travelled and time spent in the light chamber and entries into light and dark chambers were recorded.

\section{Tail suspension test (TST) and forced swimming test (FST)}

The TST and FST were carried out to assess depression behaviours in the offspring. The TST and FST were performed according to the previous report (Steru et al. 1985, YankelevitchYahav et al. 2015). In TST, the mice were suspended on an apparatus by their tails individually and recorded for $6 \mathrm{~min}$. In FST, mice were placed in a transparent cylinder filled with $18 \mathrm{~cm}$ height of $18-26^{\circ} \mathrm{C}$ water and videotaped for $6 \mathrm{~min}$. The animal behaviours in the last 4 min were analysed, and the time of struggle (escape-related behaviour) in blind was quantified for both TST and FST. Immobility time $=240 \mathrm{~s}-$ struggle time.

\section{Sucrose preference test (SPT)}

The SPT was performed to assess depression behaviours in the offspring (Liu et al. 2018). During the SPT, the mice were individually housed. On the first day of the test, the mice were given two bottles contained 1\% sucrose and pure water, respectively. After that, the mice were deprived of drink for $12 \mathrm{~h}$. And then, two bottles that contained $1 \%$ sucrose or water were resupplied and switched the location for each other. Twentyfour hours later, the weights of the bottles were measured. The sucrose preference index was calculated using the equation ( $\Delta$ weight of sucrose $) /(\Delta$ weight of sucrose $+\Delta$ weight of water) $\times 100$. 


\section{Tissue collection and Western blotting}

All mice in each group were sacrificed by cervical dislocation after anaesthetized at the age of 3 months and 18 months by i.p. injection 1.25\% tribromoethanol (M2910, Nanjing Aibei Biotechnology Co., Ltd, Nanjing, China) after completion of behavioural assessment. Hippocampal and PFC tissues were isolated immediately from the brains of offspring and frozen directly in liquid nitrogen. Half of the hippocampus and PFC from each mouse was used for RNA extraction, and the other half for protein extraction. Protein was extracted using RIPA lysis buffer (P0013B; Beyotime, Wuhan, China). Samples were separated using SDS-PAGE at 80-120 V for $90 \mathrm{~min}$ and transferred onto PVDF membranes at $220 \mathrm{~mA}$ for $30 \mathrm{~min}$. The primary antibodies included BDNF antibody (1:2000, ab108319, Abcam ), GDNF antibody (1:1000, ab176564, Abcam), NGF antibody (1:1000, ab52918, Abcam), and GAPDH antibody (1:5000, 10494-1-AP, ProteinTech Group, Inc., Chicago, IL, USA). Primary antibodies were incubated overnight at $4^{\circ} \mathrm{C}$, and secondary antibodies were incubated for $1 \mathrm{~h}$ at room temperature. The signals were visualized by an ECL system (Amersham Imager 600, GE Healthcare Life Sciences ).

\section{RNA sequencing and quantitative real-time PCR}

Total RNA was isolated from the hippocampus using TRIzol reagent (15596026, Invitrogen). The quality of total RNA was confirmed by agarose gel electrophoresis, and RNA was used for the construction of cDNA library. RNA sequencing (RNA-Seq) was performed in the hippocampus of 18 months old offspring. The sequencing was conducted on an Illumina Nova6000 system and performed by Genergy biological technology Co., Ltd. (Shanghai, China). The reads were trimmed and then mapped to the entire genome. Differential expression genes (DEGs) were determined by fold change $>1$ and $P$ value $<0.05$. GO and KEGG pathway enrichment analyses were performed. The Venn diagram was drawn online (http://jvenn.toulouse.inra.fr/app/example.html) (Bardou et al. 2014).

Total RNA was reverse transcribed using a PrimeScript RT reagent Kit with gDNA Eraser (RR047A, Takara, Japan). The TB green Premix EX Taq kit (RR420A, Takara, Japan) was used for PCR. Quantitative real-time PCR (qRT-PCR) reactions were run on Applied Biosystems QuantStudio 7 Flex PCR systems (Thermo Fisher Scientific Inc.). The primer sequences were listed in Supplementary Table 1 (see section on supplementary materials given at the end of this article).

\section{Statistical analysis}

Statistical analyses were conducted using GraphPad Prism 8.0. Data are presented as the mean \pm S.E.M. Statistical analyses were performed by non-parametric Kruskal-Wallies test followed by Mann-Whitney test for behavioural results or one-way ANOVA with Tukey's test for post hoc comparisons for $\mathrm{qPCR}$ and Western blotting results. Significance was set at $P<0.05$.

\section{Results}

Young male offspring conceived by ART did not show
any alteration in anxiety and depression tests

At the age of 3 months, the mice in the IVF-ET and IVFFET groups displayed similar locomotion with NC group in the OFT (Supplementary Fig. 1). Meanwhile, no differences in performance were observed in the MWM among three groups (Supplementary Fig. 1), indicating similar spatial learning abilities. In the EPM test, mice in the three groups spent similar time and distance in the open arms (Supplementary Fig. 1). There were no differences in the immobile time in TST among the three groups (Supplementary Fig. 1). Taken together, the results showed that male mice conceived by ART did not show any alteration in anxiety and depression tests at the age of 3 months.

\section{Aged male offspring conceived by ART displayed increased anxiety-like behaviours}

Figure $2 \mathrm{~A}$ displays the representative trajectory diagrams in the OFT for the male mice offspring at 18 months old. At the age of 18 months, mice in the three groups travelled similar distances and moved with similar velocities in the OFT (Fig. 2B and C). The percentage of activity also showed no significant differences (Fig. 2D). Similarly, there were no significant differences in the MWM on either training days or test days at the age of 18 months (Supplementary Fig. 2). Compared with NC-conceived mice, ART-conceived mice displayed similar locomotion and spatial learning abilities.

There was a significant difference in distance travelled in the centre zone in the IVF-FET group compared with the NC group (Fig. 2E). Although no differences were observed in the frequency of entering into the centre zone among the three groups (Fig. 2F), there was a significant difference in distance travelled in the centre zone between the NC and IVF-FET groups (Fig. 2G). Less time and distance spent in the centre zone indicated increased anxiety-like behaviours in aged male offspring conceived by IVF-FET.

Moreover, EPM and L/DTT were performed to further assess the anxiety levels for mice at 18 months old. Representative heatmaps for activity in the EPM are shown in Fig. 3A. In the EPM results, no significant differences were detected in the total distance (Fig. 3B). The mice in the IVF-ET group travelled less distance than these in the NC group, and similar distance compared with the IVF-FET group (Fig. 3C). The results also revealed significant differences in distance travelled, entries into, and time spent in the open arms between the IVF-FET group and the NC group (Fig. 3C, D, and E). The mice in the IVF-ET and IVF-FET groups exhibited increased anxiety-like behaviours with varying degrees of severity for less distance, entries, and time in the open arms. 
A
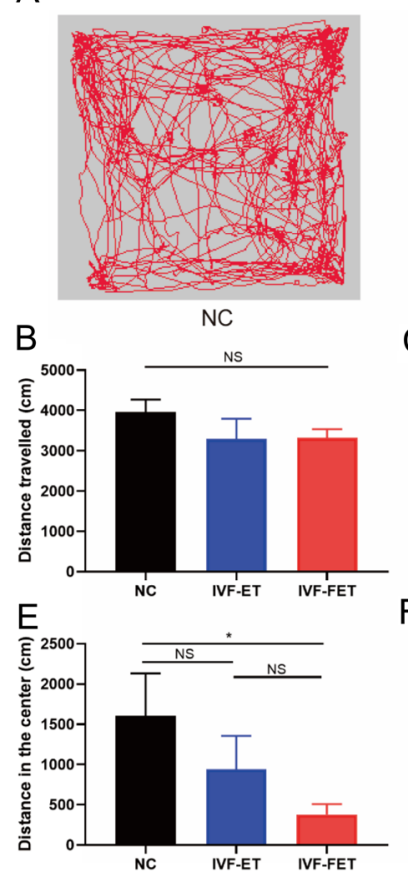

18 months old

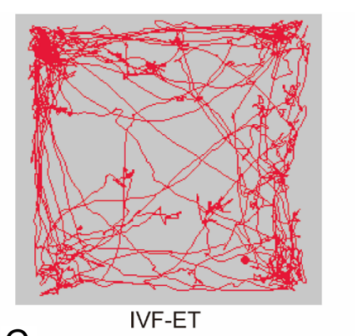

C
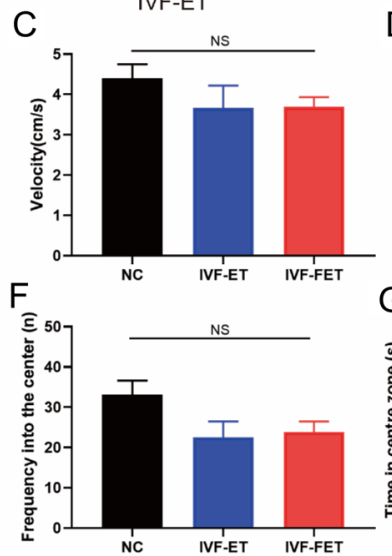

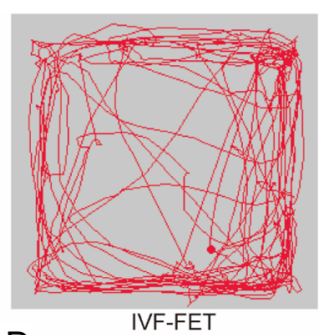

D

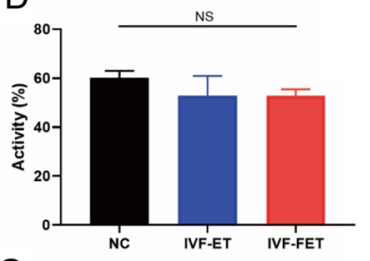

G

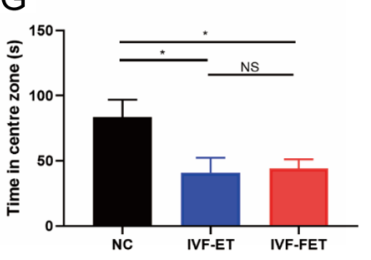

Figure 2 Open field test (OFT) results of male mice offspring at 18 months old. (A) Representative trajectory diagrams in the OFT for the three groups (NC, IVF-ET, and IVF-FET). (B) Total distance travelled in the OFT. (C) Average velocity in the OFT. (D) Percentage of activity in the OFT. (E, F, and G) The distance $(\mathrm{E})$, time $(\mathrm{F})$, and entries $(\mathrm{G})$ in the centre zone. All data are presented as the mean \pm S.E.M. ( $n=7$ mice per group). NS: $P>0.05$,

$* P<0.05$.
In the L/DTT, aged mice in the IVF-ET and IVF-FET groups travelled less distance and spent less time in the light chamber than those in the $\mathrm{NC}$ group (Fig. 3F and G). Meanwhile, there was no significant difference in distance and time in the light chamber between the IVF-ET and IVF-FET groups. Although mice in the three groups entered into the light chamber at similar times, the ratio of entries into the light chamber in the IVF-ET and IVF-FET groups seemed to be lower than those in the NC group (Fig. $3 \mathrm{H}$ and I). These data furtherly suggested that aged male offspring conceived by ART displayed anxiety-like behaviours.

\section{Increased depression-like behaviours in aged male offspring conceived by ART}

For 18 months old mice, there was a significant increase in immobility time in both the TST and FST in the IVF-ET and IVF-FET groups compared with those in the NC group (Fig. 4A and B), indicating increased depressionlike behaviours in the aged male offspring conceived by ART. The sucrose preference index from the SPT also showed a similar trend-wise in the TST and FST (Fig. 4C). Furthermore, the male offspring in the IVF-FET group exhibited more severe depression level than those in the IVF-ET group in the FST and SPT.

\section{Decreased neurotrophin protein expression levels in the hippocampus and PFC of aged male mice offspring in the IVF-ET and IVF-FET groups}

We examined expression levels of three key neurotrophin proteins (BDNF, GDNF, and NGF) in the hippocampus and PFC of male mice offspring at 3 and 18 months old via Western blotting (Fig. 5 and Supplementary Fig. 3). The expression level of GDNF was significantly reduced in the hippocampus of male mice offspring in the IVF-FET group compared with NC and IVF-ET (Supplementary Fig. 3A), while no significant differences were found in the PFC in the three groups (Supplementary Fig. 3B). Meanwhile, we found that the protein expression levels of BDNF, GDNF, and NGF in the aged male mice offspring were decreased in the hippocampus from the offspring in the IVF-ET and IVF-FET groups (Fig. 5A), although there was no significant difference between the IVF-ET and IVF-FET groups. In the PFC, the expression levels of GDNF and NGF, but not BDNF, were reduced in the mice from both the IVF-ET and IVF-FET groups (Fig. 5B). The data suggested that decreased expression levels of BDNF, GDNF, and NGF were concordant with the increased anxiety and depression-like behaviours in aged male mice offspring conceived by ART.

\section{Transcriptional alterations in the hippocampus of aged offspring in the IVF-ET and IVF-FET groups}

As there is a more severe reduction of neurotrophins in the hippocampus than in the PFC, we applied RNA-Seq to explore the gene expression profile changes in the hippocampus of aged offspring in IVF-ET and IVF-FET groups. And then, we selected 5 DEGs to validate the results of RNA-Seq. The results of qRT-PCR resonated with the data of RNA-Seq (Supplementary Fig. 4A).

Compared with NC group, 1625 genes were upregulated, and 159 genes were downregulated in 
A

18 months old

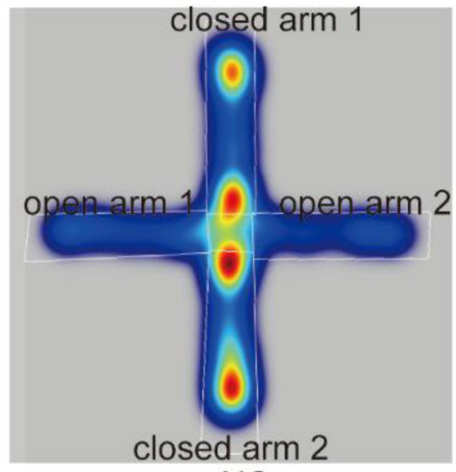

NC

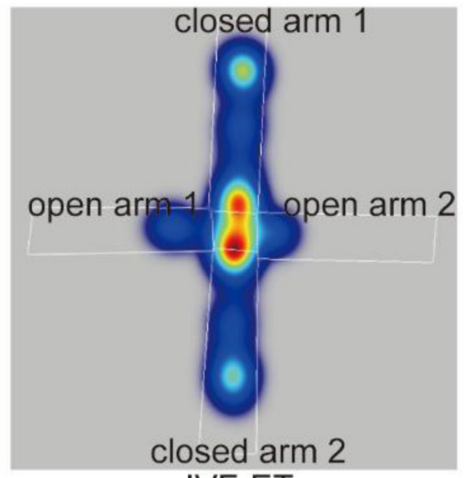

IVF-ET

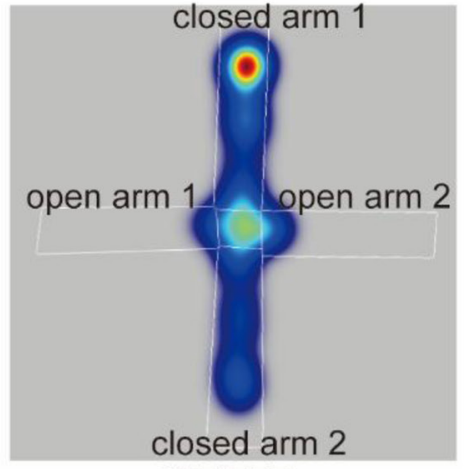

IVF-FET
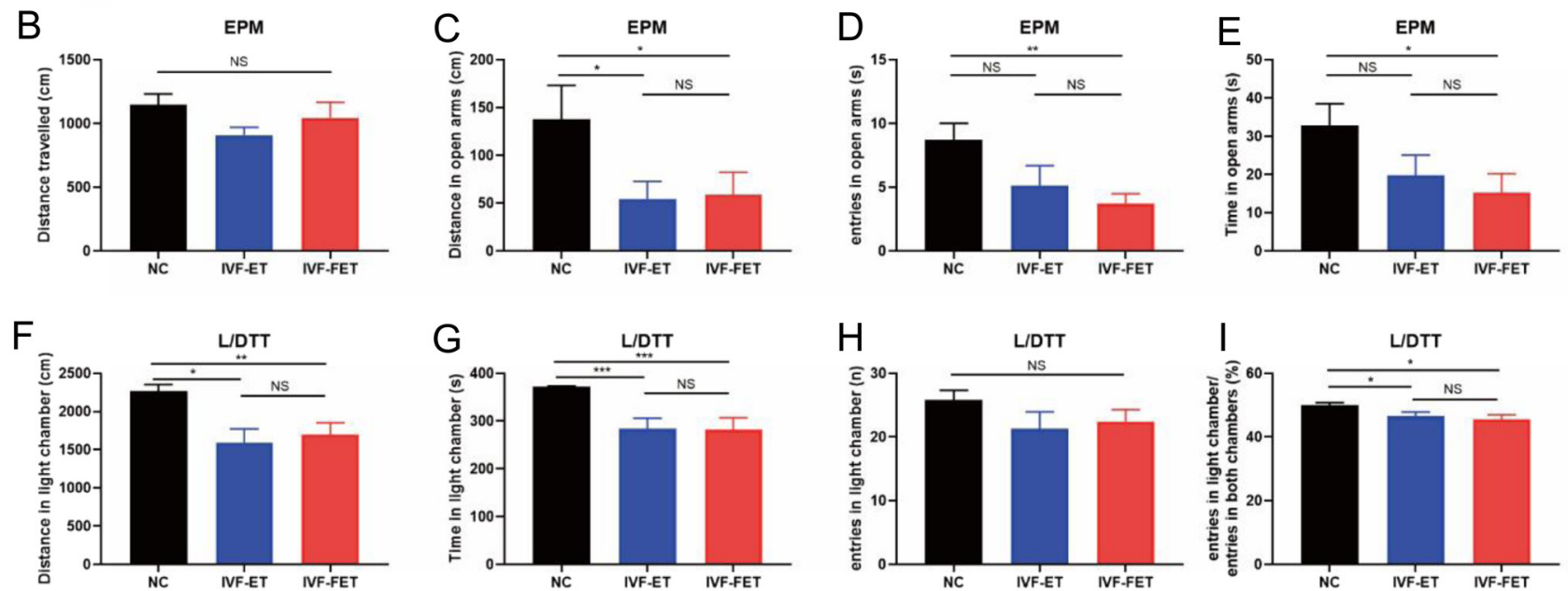

Figure 3 Elevated plus maze (EPM) and light/dark transition test (L/DTT) results of male mice offspring at 18 months old. (A) Representative heatmaps in the EPM for the three groups (NC, IVF-ET, and IVF-FET). (B) Total distance travelled in open and closed arms. (C, D, and E) Distance $(C)$, entries (D), and time (E) in open arms. (F, G, and H) Distance (F), time (G), and entries (H) in the light chamber in the L/DTT. (I) The proportion of entries into the light chamber relative to all entries into both sides. All data are presented as the mean \pm S.E.M. $(n=7$ mice per group). NS: $P>0.05, * P<0.05, * * P<0.01, * * * P<0.001$.

IVF-ET group (supplementary Fig. 4B), meanwhile, 661 (480 genes upregulated and 181 genes downregulated) DEGs were identified in the IVF-FET group compared with the NC group (Supplementary Fig. 4C). Venn analysis showed that there are 305 DEGs (272 upregulated genes and 33 downregulated genes) between IVF-ET and IVFFET groups compared with NC (Supplementary Fig. 4D and $\mathrm{E})$.

Top 15 GO terms are shown in Fig. 6A (IVF-ET group vs NC group) and Fig. 6B (IVF-FET group vs NC group).
Protein binding, developmental process, ion binding, anatomical structure development, multicellular organism development, and system development were listed in coexisted enriched top 15 GO terms analysis in the overlapped DEGs dataset between the IVF-ET and IVF-FET groups. Furthermore, DEGs were also analysed using KEGG database. We found that most enriched KEGG terms were overlapped in the two DEGs datasets (Fig. 6C). Among the 15 coexisted KEGG pathways, six pathways were associated with the nervous system,
A

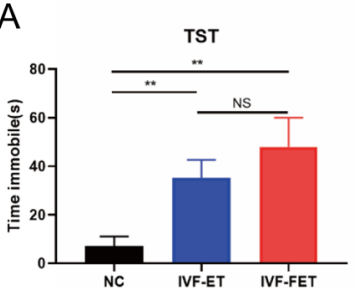

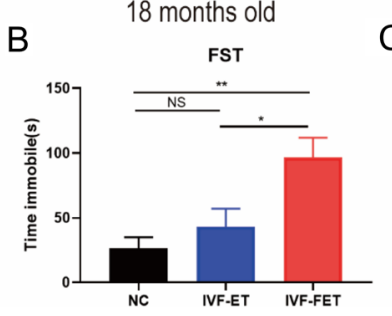

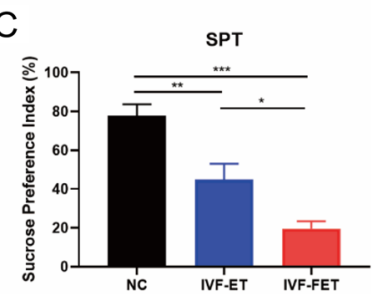

Figure 4 Tail suspension test (TST), force swimming test (FST), and sucrose preference test (SPT) results of male mice offspring at 18 months old. (A and B) Immobility time in the TST (A) and FST (B). (C) Sucrose preference index in SPT. All data are presented as the mean \pm S.E.M. $(n=7$ mice per group) NS: $P>$ $0.05, * P<0.05, * * P<0.01,{ }^{* * *} P<0.001$. 

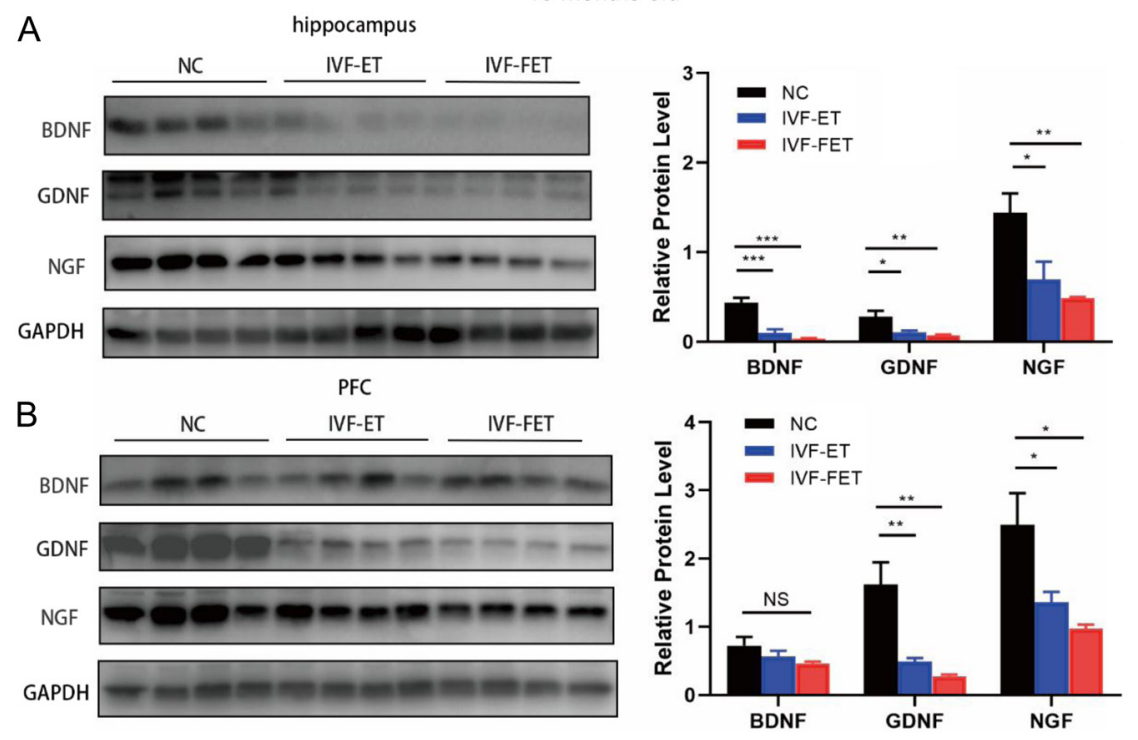

\begin{abstract}
Figure 5 Western blotting results of three neurotrophins in the hippocampus and PFC of male mice offspring at 18 months old. Representative images of BDNF, GDNF, and NGF in the hippocampus (A) and PFC (B). All data are presented as the mean \pm S.E.M. $(n=4$ mice per group). NS: $P>0.05, * P<0.05$, ${ }^{* *} P<0.01,{ }^{* * *} P<0.001$.
\end{abstract}

GAPDH

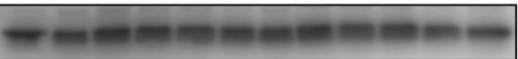
BDNF

including ECM-receptor interaction, focal adhesion, PI3K/AKT signalling pathway, phagosome, cell adhesion molecules, and cellular senescence (Fig. 6D). Among the three groups, totally 73 genes were involved in the 6 KEGG pathways. Compared with the NC group, 55 and 33 genes were enriched in the IVF-ET and IVFFET groups, respectively. All these genes were listed in Supplementary Tables 2 and 3.

\section{Discussion}

Herein, we found that ART-conceived aged male mice offspring exhibited increased anxiety and depressionlike behaviours compared with natural conception, extend the results from prior studies, which had implied increased risks of neurodevelopmental disease in the children born after ART (Strömberg et al. 2002, Zhu et al. 2009, Sandin et al. 2013).

Several mouse models have been established to investigate the effects of in vitro embryo culture (Ecker et al. 2004, Fernandez-Gonzalez et al. 2004), blastomere biopsy (Yu et al. 2009, Sampino et al. 2014, Wu et al. 2014), and intracellular sperm insemination (FernandezGonzalez et al. 2008, Lewon et al. 2020), demonstrating that multiple procedures in ART enabled to increase anxiety level and deficit in learning abilities in offspring conceived by ART (Farquhar \& Marjoribanks 2018). A previous study reported the reduced expression of MAOA, CRFR2, and GABA markers in the hypothalamus and cortex, which were associated with high risk of anxiety and depression in mice conceived by IVF-ET compared with these in the natural pregnancy (Strata et al. 2015). Meanwhile, the levels of anxiety and depression were aggravating during ageing in mouse offspring conceived by IVF-ET (Fernandez-Gonzalez et al. 2004, Yu et al. 2011). These results are in line with our new findings. Meanwhile, our study first reported behavioural alterations in FETconceived mice offspring. Mice offspring in IVF-FET group exhibited similar behaviroual alterations. Mice conceived by IVF-FET predisposed to depression, compared with IVF-ET. The potential harms of frozen and thawed process on the embryos may endow differential predisposition. Nevertheless, the exact molecular mechanisms still need further research in future.

BDNF, GDNF, and NGF are the most abundant neurotrophins that existed in CNS and involved in the pathophysiology of mood and other stress-related disorders (Bjorkholm \& Monteggia 2016, Castren \& Kojima 2017, von Bohlen Und Halbach \& von Bohlen Und Halbach 2018). It has been demonstrated that the declination of these neurotrophins is highly correlated with the occurrence of anxiety and depression (Castren \& Kojima 2017). At the age of 3 months old, ARTconceived male mice offspring did not exhibit alterations in behavioural assessment. Western blotting results revealed that GDNF was significantly decreased in the hippocampus of mice offspring in the IVF-FET groups compared with the other groups, while neurotrophins protein expression levels of PFC were similar in the three groups. At the age of 18 months old, ART-conceived male mice offspring exhibited increased anxiety and depression-like behaviours than natural conception. GDNF and NGF were significantly downregulated in the hippocampus and PFC, which might contribute to increase the anxiety and depression levels in the offspring from IVF-ET and IVF-FET groups. More severe alteration of neurotrophins protein expression levels of mice offspring at 18 months old than 3 months old was consistent with increased anxiety and depression-like behaviours in the aged offspring.

At the age of 3 months old, male mice offspring in IVF-FET group displayed decreased GDNF protein 


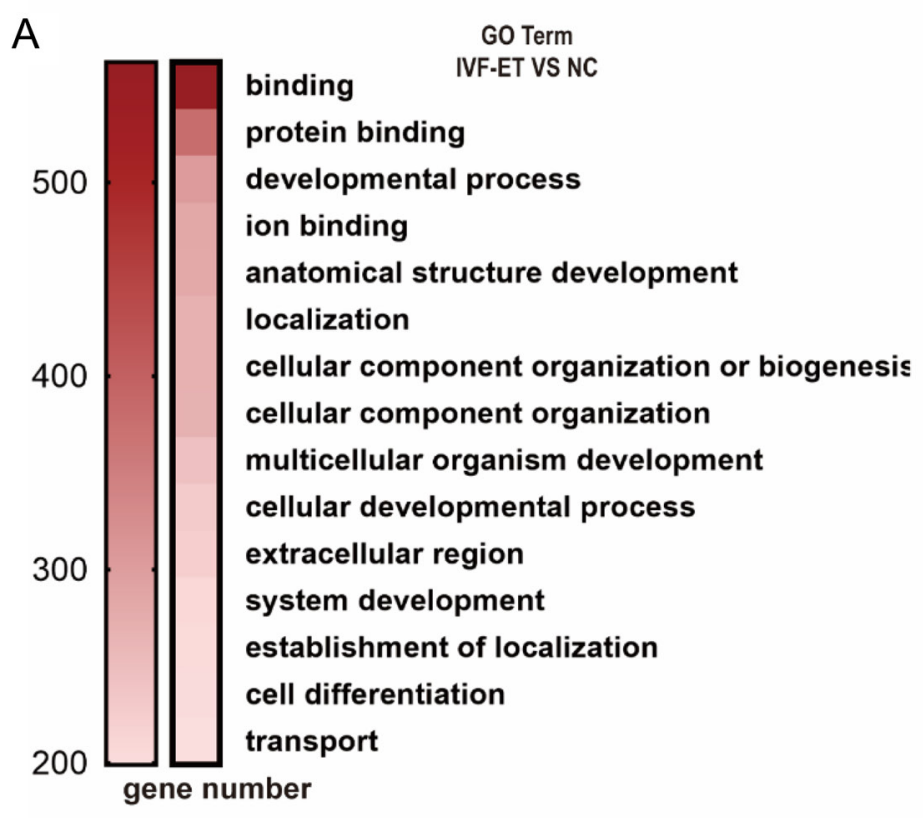

C

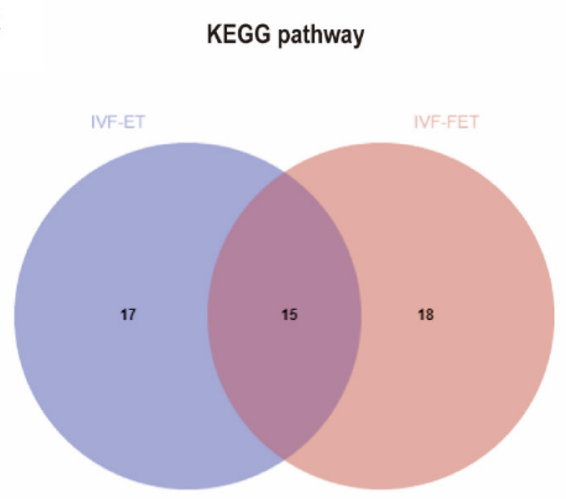

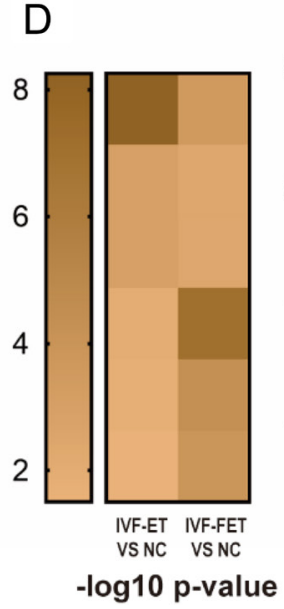

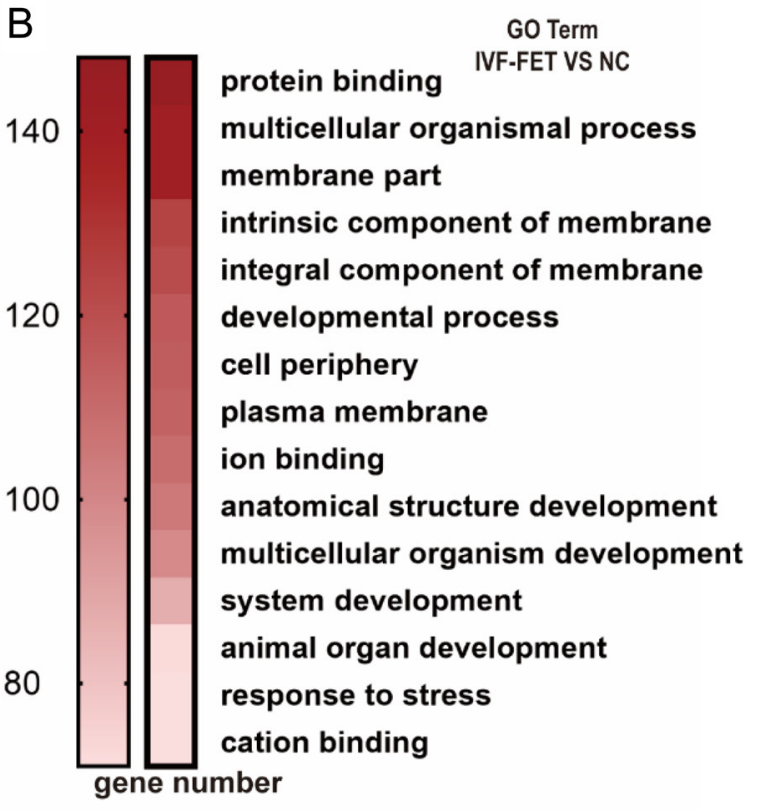

KEGG pathway

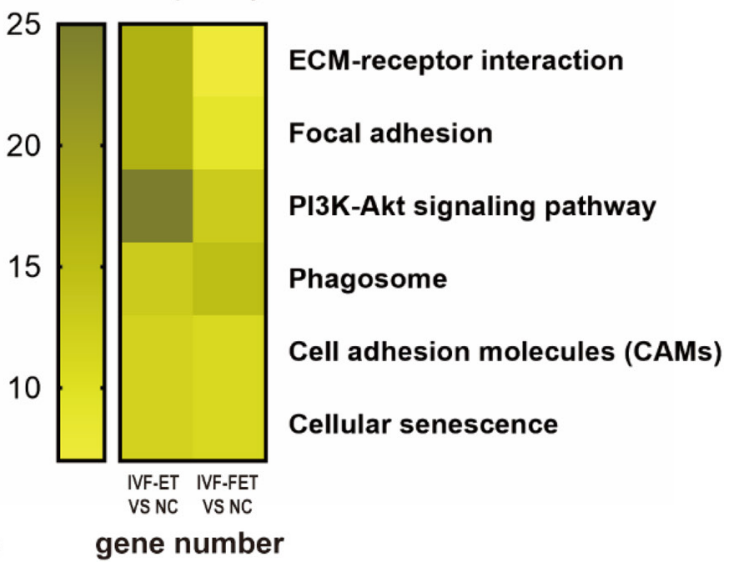

Figure 6 Gene ontology (GO) and Kyoto encyclopaedia of genes and genomes (KEGG) pathway enrichment analysis in the hippocampus of male mice offspring at 18 months old. The top 15 enriched GO terms ranked by the number of differential expression genes (DEGs) in the IVF-ET group (A) and IVF-FET group (B) compared with the NC group. (C) Venn diagram showed the enriched KEGG pathways terms in the two DEGs. (D) The heatmaps showed the $P$-values and number of DEGs in overlapped KEGG pathways terms ( $n=3$ mice per group).

expression level in the hippocampus compared with NC and IVF-ET groups, although no behavioural alterations were observed. Reduced GDNF in CNS or peripheral serum could be a potential biomarker of mood disorder, especially for depression (Sun et al. 2019, Idemoto et al. 2021, Nedic Erjavec et al. 2021). Moreover, GDNF has been proven to promote the survival, differentiation, and neurite growth, most notably of dopaminergic neurons both in vitro and in vivo (Haniu et al. 1996, Nakajima et al. 2001, Consales et al. 2007). Thus, we speculate that the depression phenotype in aged ARTconceived mice offspring might be associated with the reduced GDNF and functions of dopaminergic neurons. At the age of 18 months old, ART-conceived male mice offspring displayed decreased BDNF protein expression level in the hippocampus compared with NC. Comparable expression level of BDNF in the PFC could be contributed to its complex and fruitful roles in the nervous system. For instance, BDNF is involved in hippocampus-dependent spatial learning and memory (Bjorkholm \& Monteggia 2016, von Bohlen Und Halbach \& von Bohlen Und Halbach 2018).

GO and KEGG analyses in DEGs provided the potential pathways associated with altered behaviours conceived by ART and advanced age. According to previous research, the overlapped six KEGG pathways 
in the overlapped DEGs datasets between the IVF-ET and IVF-FET groups were associated with the functions of nervous system. For instance, the ECMreceptor interaction pathway plays a pivotal role in the pathogenesis of several neurodegenerative and neuroinflammatory disorders, as the direct or indirect control of cellular processes such as adhesion, migration, differentiation, proliferation, and apoptosis (Kerrisk et al. 2014, Mardpour et al. 2019, Sun et al. 2020, Virtuoso et al. 2020, Su et al. 2021). Focal adhesion, phagosome, CAMs, and cellular senescence are enriched KEGG terms. These KEGG pathways interact with each other and participate in the ECM-receptor interaction pathway (Kerrisk et al. 2014, Mardpour et al. 2019, Sun et al. 2020, Virtuoso et al. 2020, Su et al. 2021). Furthermore, PI3K/AKT signalling pathway is strongly associated with anxiety and depression behaviours through hippocampal plasticity, cell growth, proliferation, survival, and metabolism (Gimenez-Llort et al. 2020, Neis et al. 2020, Palumbo et al. 2021).

Actually, we did not exactly interpret why the behavioural alterations occurred in the aged ARTconceived male mice offspring rather than adult offspring. Based on our analysis, we presume the ART procedure as 'first hit' in early life and ageing as 'second hit' for the offspring. The 'second hit' framework was a crucial theory to explain how lifelong health can be adversely affected by a series of 'hits' (Winett et al. 2016). In other words, when suffered with ageing, ARTconceived offspring seem biased towards anxiety and depression.

However, there are several limitations in our present study. First, ART procedures in mice are similar to humans, but does not recapture all procedures in the clinic. Different ovarian stimulation protocols and genetic backgrounds may affect the behavioural results in offspring for humans. Secondly, in addition to congenital background, there are many acquired aspects that might be related to anxiety and depression for humans, including home environment, educational background, life quality, income level, alcohol abuse, and stressful life events (Ransome et al. 2017, Czamara et al. 2021, Haugan et al. 2021, Sparling et al. 2021). Thirdly, we only assessed behaviours at 3 and 18 months old for offspring. We could not identify the onset time of anxiety and depression phenotypes in this study.

Nevertheless, our study had several strengths. The most important was that the mouse model excluded confounding effects of ovarian stimulation protocols and genetic backgrounds. Our current findings indicated that male offspring conceived by ART exhibited increased anxiety and depression-like behaviours when they were aged and lower expression of three neurotrophic factors which might contribute to the phenotypes occurred. This work paves the way to further investigate the precise mechanisms underpinning anxiety and depression in aged male offspring conceived by ART.

\section{Supplementary materials}

This is linked to the online version of the paper at https://doi. org/10.1530/REP-21-0175.

\section{Declaration of interest}

The authors declare that there is no conflict of interest that could be perceived as prejudicing the impartiality of the research reported.

\section{Funding}

This work was supported by the National Key Research and Development Project (no. 2017YFC1001300 to H-F H, no. 2018YFC1004900 to W-L Z), the National Natural Science Foundation of China (no. 81661128010 to $\mathrm{H}-\mathrm{F} \mathrm{H}$, no. 81701504 to W-L Z, no. 82088102 to H-F H), the Shanghai Municipal Science and Technology Innovation Action Plan (no. 20XD1424100 to Y-T W), Shanghai Shenkang Hospital Developmental Center (no. SHDC12018X17 to Y-T W), General Program of Shanghai Municipal Commission of Health and Family Planning (no. 201840210), General Program of Shanghai Jiaotong University Medical Engineering Cross Fund (no. YG2019GD04 to Y-T W), Chinese Academy of Medical Sciences Research Unit (no. 2019RU056), Shanghai Jiao Tong University, CAMS Innovation Fund for Medical Sciences (CIFMS) (no. 2019-I2M-5-064) and Shanghai Municipal Key Clinical Specialty, Shanghai, China.

\section{Author contribution statement}

$\mathrm{N}-\mathrm{X}$ Q, Y-R Z, W-H S, and Z-Y Z designed and performed experiments and analysed data. N-X Q, W-L Z, and Z-Y Z wrote and edited the manuscript. K-X $Z$ and $W-H ~ S$ contributed to data analysis. C-J Y, X L, Z-H D, Y-T M, J-L Y, and C-L Z contributed to conducting the experiment. $X-M L, J-Z S$, and G-L D contributed to the study design, discussion, and conducted experiments. $\mathrm{Y}-\mathrm{T} \mathrm{W}$ and $\mathrm{H}-\mathrm{F} \mathrm{H}$ designed and supervised the research, contributed to discussion, and edited the manuscript. $\mathrm{H}-\mathrm{F} \mathrm{H}$ is the guarantor of this work and has full access to all data in the study and takes responsibility for the integrity and accuracy of data analyses.

\section{References}

Aljahdali A, Airina RKRI, Velazquez MA, Sheth B, Wallen K, Osmond C, Watkins AJ, Eckert JJ, Smyth NR \& Fleming TP 2020 The duration of embryo culture after mouse IVF differentially affects cardiovascular and metabolic health in male offspring. Human Reproduction 35 2497-2514. (https://doi.org/10.1093/humrep/deaa205)

Allen SJ, Watson JJ, Shoemark DK, Barua NU \& Patel NK 2013 GDNF, NGF and BDNF as therapeutic options for neurodegeneration. Pharmacology and Therapeutics 138 155-175. (https://doi.org/10.1016/j. pharmthera.2013.01.004)

Andreae LC \& Basson MA 2018 Sex bias in autism: new insights from Chd8 mutant mice? Nature Neuroscience 21 1144-1146. (https://doi. org/10.1038/s41593-018-0217-y)

Angelucci F, Mathé AA \& Aloe L 2004 Neurotrophic factors and CNS disorders: findings in rodent models of depression and schizophrenia. 
Progress in Brain Research 146 151-165. (https://doi.org/10.1016/ s0079-6123(03)46011-1)

Autry AE \& Monteggia LM 2012 Brain-derived neurotrophic factor and neuropsychiatric disorders. Pharmacological Reviews 64 238-258. (https://doi.org/10.1124/pr.111.005108)

Ayanlaja AA, Zhang B, Ji G, Gao Y, Wang J, Kanwore K \& Gao D 2018 The reversible effects of glial cell line-derived neurotrophic factor (GDNF) in the human brain. Seminars in Cancer Biology 53 212-222. (https://doi. org/10.1016/j.semcancer.2018.07.005)

Barbeito S, Vega P, Sanchez-Gutierrez T, Becerra JA, Gonzalez-Pinto A \& Calvo A 2021 A systematic review of suicide and suicide attempts in adolescents with psychotic disorders. Schizophrenia Research 235 80-90. (https://doi.org/10.1016/j.schres.2021.07.029)

Bardou P, Mariette J, Escudie F, Djemiel C \& Klopp C 2014 jvenn: an interactive Venn diagram viewer. BMC Bioinformatics 15 293. (https:// doi.org/10.1186/1471-2105-15-293)

Baxter AJ, Scott KM, Vos T \& Whiteford HA 2013 Global prevalence of anxiety disorders: a systematic review and meta-regression. Psychological Medicine 43 897-910. (https://doi.org/10.1017/S003329171200147X)

Berntsen S, Soderstrom-Anttila V, Wennerholm UB, Laivuori H, Loft A, Oldereid NB, Romundstad LB, Bergh C \& Pinborg A 2019 The health of children conceived by ART: 'the chicken or the egg?' Human Reproduction Update 25 137-158. (https://doi.org/10.1093/humupd/ dmz001)

Bjorkholm C \& Monteggia LM 2016 BDNF - a key transducer of antidepressant effects. Neuropharmacology 102 72-79. (https://doi. org/10.1016/j.neuropharm.2015.10.034)

Boivin JR, Piekarski DJ, Wahlberg JK \& Wilbrecht L 2017 Age, sex, and gonadal hormones differently influence anxiety- and depression-related behavior during puberty in mice. Psychoneuroendocrinology 85 78-87. (https://doi.org/10.1016/j.psyneuen.2017.08.009)

Brandeis R, Brandys Y \& Yehuda S 1989 The use of the Morris water Maze in the study of memory and learning. International Journal of Neuroscience 48 29-69. (https://doi.org/10.3109/00207458909002151)

Carrier N, Wang X, Sun L \& Lu XY 2015 Sex-specific and estrous cycledependent antidepressant-like effects and hippocampal Akt signaling of leptin. Endocrinology 156 3695-3705. (https://doi.org/10.1210/ EN.2015-1029)

Castren E \& Kojima M 2017 Brain-derived neurotrophic factor in mood disorders and antidepressant treatments. Neurobiology of Disease $\mathbf{9 7}$ 119-126. (https://doi.org/10.1016/j.nbd.2016.07.010)

Castren E \& Monteggia LM 2021 Brain-derived neurotrophic factor signaling in depression and antidepressant action. Biological Psychiatry 90 128-136. (https://doi.org/10.1016/j.biopsych.2021.05.008)

Cerny D, Sartori C, Rimoldi SF, Meister T, Soria R, Bouillet E, Scherrer U \& Rexhaj E 2017 Assisted reproductive technologies predispose to insulin resistance and obesity in male mice challenged with a high-fat diet. Endocrinology 158 1152-1159. (https://doi.org/10.1210/en.20161475)

Chen M, Wu L, Zhao J, Wu F, Davies MJ, Wittert GA, Norman RJ, Robker RL \& Heilbronn LK 2014 Altered glucose metabolism in mouse and humans conceived by IVF. Diabetes 63 3189-3198. (https://doi. org/10.2337/db14-0103)

Consales C, Volpicelli F, Greco D, Leone L, Colucci-D'Amato L, PerroneCapano C \& Di Porzio U 2007 GDNF signaling in embryonic midbrain neurons in vitro. Brain Research 1159 28-39. (https://doi.org/10.1016/j. brainres.2007.04.071)

Crawley J \& Goodwin FK 1980 Preliminary report of a simple animal behavior model for the anxiolytic effects of benzodiazepines. Pharmacology, Biochemistry, and Behavior 13 167-170. (https://doi. org/10.1016/0091-3057(80)90067-2)

Cui L, Zhou W, Xi B, Ma J, Hu J, Fang M, Hu K, Qin Y, You L, Cao Y et al. 2020 Increased risk of metabolic dysfunction in children conceived by assisted reproductive technology. Diabetologia 63 2150-2157. (https:// doi.org/10.1007/s00125-020-05241-1)

Czamara D, Tissink E, Tuhkanen J, Martins J, Awaloff Y, Drake AJ, Khulan B, Palotie A, Winter SM, Nemeroff CB et al. 2021 Combined effects of genotype and childhood adversity shape variability of DNA methylation across age. Translational Psychiatry 11 88. (https://doi.org/10.1038/ s41398-020-01147-z)

Datta S, Samanta D, Tiwary B, Chaudhuri AG \& Chakrabarti N 2019 Sex and estrous cycle dependent changes in locomotor activity, anxiety and memory performance in aged mice after exposure of light at night. Behavioural Brain Research 365 198-209. (https://doi.org/10.1016/j. bbr.2019.03.015)

de Azevedo Cardoso T, Mondin TC, Wiener CD, Marques MB, Fucolo Bde Á, Pinheiro RT, De Souza LDM, Da Silva RA, Jansen K \& Oses JP 2014 Neurotrophic factors, clinical features and gender differences in depression. Neurochemical Research 39 1571-1578. (https://doi. org/10.1007/s11064-014-1349-4)

Donjacour A, Liu X, Lin W, Simbulan R \& Rinaudo PF 2014 In vitro fertilization affects growth and glucose metabolism in a sex-specific manner in an outbred mouse model. Biology of Reproduction 9080. (https://doi.org/10.1095/biolreprod.113.113134)

Duranthon V \& Chavatte-Palmer P 2018 Long term effects of ART: what do animals tell us? Molecular Reproduction and Development 85 348-368. (https://doi.org/10.1002/mrd.22970)

Ecker DJ, Stein P, Xu Z, Williams CJ, Kopf GS, Bilker WB, Abel T \& Schultz RM 2004 Long-term effects of culture of preimplantation mouse embryos on behavior. PNAS 101 1595-1600. (https://doi.org/10.1073/ pnas.0306846101)

Farquhar C \& Marjoribanks J 2018 Assisted reproductive technology: an overview of cochrane reviews. Cochrane Database of Systematic Reviews 8 CD010537. (https://10.1002/14651858.CD010537.pub5)

Faye C, Mcgowan JC, Denny CA \& David DJ 2018 Neurobiological mechanisms of stress resilience and implications for the aged population. Current Neuropharmacology 16 234-270. (https://doi.org/10.2174/157 0159X15666170818095105)

Fernandez-Gonzalez R, Moreira P, Bilbao A, Jimenez A, Perez-Crespo M, Ramirez MA, Rodriguez De Fonseca F, Pintado B \& Gutierrez-Adan A 2004 Long-term effect of in vitro culture of mouse embryos with serum on mRNA expression of imprinting genes, development, and behavior. PNAS 101 5880-5885. (https://doi.org/10.1073/pnas.0308560101)

Fernandez-Gonzalez R, Moreira PN, Perez-Crespo M, Sanchez-Martin M, Ramirez MA, Pericuesta E, Bilbao A, Bermejo-Alvarez P, De Dios Hourcade J, De Fonseca FR et al. 2008 Long-term effects of mouse intracytoplasmic sperm injection with DNA-fragmented sperm on health and behavior of adult offspring. Biology of Reproduction 78 761-772. (https://doi.org/10.1095/biolreprod.107.065623)

Ferrari AJ, Somerville AJ, Baxter AJ, Norman R, Patten SB, Vos T \& Whiteford HA 2013 Global variation in the prevalence and incidence of major depressive disorder: a systematic review of the epidemiological literature. Psychological Medicine 43 471-481. (https://doi.org/10.1017/ S0033291712001511)

Garber J, Brunwasser SM, Zerr AA, Schwartz KT, Sova K \& Weersing VR 2016 Treatment and prevention of depression and anxiety in youth: test of cross-over effects. Depression and Anxiety 33 939-959. (https://doi. org/10.1002/da.22519)

Gerhard DM, Meyer HC \& Lee FS 2021 An adolescent sensitive period for threat responding: impacts of stress and sex. Biological Psychiatry 89 651-658. (https://doi.org/10.1016/j.biopsych.2020.10.003)

Gimenez-Llort L, Santana-Santana M \& Bayascas JR 2020 The impact of the PI3K/Akt signaling pathway in anxiety and working memory in young and middle-aged PDK1 K465E knock-in mice. Frontiers in Behavioral Neuroscience 14 61. (https://doi.org/10.3389/fnbeh.2020.00061)

Haniu M, Hui J, Young Y, Le J, Katta V, Lee R, Shimamoto G \& Rohde MF 1996 Glial cell line-derived neurotrophic factor: selective reduction of the intermolecular disulfide linkage and characterization of its disulfide structure. Biochemistry 35 16799-16805. (https://doi.org/10.1021/ bi9605550)

Hare BD \& Duman RS 2020 Prefrontal cortex circuits in depression and anxiety: contribution of discrete neuronal populations and target regions. Molecular Psychiatry 25 2742-2758. (https://doi.org/10.1038/ s41380-020-0685-9)

Hargreave $M$, Jensen A, Hansen MK, Dehlendorff C, Winther JF, Schmiegelow K \& Kjaer SK 2019 Association between fertility treatment and cancer risk in children. JAMA 322 2203-2210. (https://doi. org/10.1001/jama.2019.18037)

Harro J 2019 Animal models of depression: pros and cons. Cell and Tissue Research 377 5-20. (https://doi.org/10.1007/s00441-018-2973-0)

Hart R \& Norman RJ 2013a The longer-term health outcomes for children born as a result of IVF treatment. Part II - Mental health and development outcomes. Human Reproduction Update 19 244-250. (https://doi. org/10.1093/humupd/dmt002) 
Hart R \& Norman RJ 2013b The longer-term health outcomes for children born as a result of IVF treatment. Part I - General health outcomes. Human Reproduction Update 19 232-243. (https://doi.org/10.1093/ humupd/dms062)

Haugan T, Muggleton S \& Myhr A 2021 Psychological distress in late adolescence: the role of inequalities in family affluence and municipal socioeconomic characteristics in Norway. PLOS ONE 16 e0254033. (https://doi.org/10.1371/journal.pone.0254033)

Himanshu, Dharmila, Sarkar D \& Nutan 2020 A review of behavioral tests to evaluate different types of anxiety and anti-anxiety effects. Clinical Psychopharmacology and Neuroscience 18 341-351. (https://doi. org/10.9758/cpn.2020.18.3.341)

Hiser J \& Koenigs M 2018 The multifaceted role of the ventromedial prefrontal cortex in emotion, decision making, social cognition, and psychopathology. Biological Psychiatry 83 638-647. (https://doi. org/10.1016/j.biopsych.2017.10.030)

Idemoto K, Niitsu T, Hata T, Ishima T, Yoshida S, Hattori K, Horai T, Otsuka I, Yamamori H, Toda S et al. 2021 Serum levels of glial cell line-derived neurotrophic factor as a biomarker for mood disorders and lithium response. Psychiatry Research 301 113967. (https://doi. org/10.1016/j.psychres.2021.113967)

Kalueff AV, Avgustinovich DF, Kudryavtseva NN \& Murphy DL 2006 BDNF in anxiety and depression. Science 312 1598-1599; author reply 1598-1599. (https://doi.org/10.1126/science.312.5780.1598)

Kerrisk ME, Cingolani LA \& Koleske AJ 2014 ECM receptors in neuronal structure, synaptic plasticity, and behavior. Progress in Brain Research 214 101-131. (https://doi.org/10.1016/B978-0-444-63486-3.00005-0)

Kheirbek MA, Klemenhagen KC, Sahay A \& Hen R 2012 Neurogenesis and generalization: a new approach to stratify and treat anxiety disorders Nature Neuroscience 15 1613-1620. (https://doi.org/10.1038/nn.3262)

Koo JW, Chaudhury D, Han MH \& Nestler EJ 2019 Role of mesolimbic brain-derived neurotrophic factor in depression. Biological Psychiatry 86 738-748. (https://doi.org/10.1016/j.biopsych.2019.05.020)

Kristiansen M \& Ham J 2014 Programmed cell death during neuronal development: the sympathetic neuron model. Cell Death and Differentiation 21 1025-1035. (https://doi.org/10.1038/cdd.2014.47)

Lewon M, Wang Y, Peters C, Peterson M, Zheng H, Wang Z, Hayes L \& Yan W 2020 Assessment of operant learning and memory in mice born through ICSI. Human Reproduction 35 2058-2071. (https://doi. org/10.1093/humrep/deaa167)

Liu MY, Yin CY, Zhu LJ, Zhu XH, Xu C, Luo CX, Chen H, Zhu DY \& Zhou QG 2018 Sucrose preference test for measurement of stressinduced anhedonia in mice. Nature Protocols 13 1686-1698. (https:// doi.org/10.1038/s41596-018-0011-z)

Mardpour S, Hamidieh AA, Taleahmad S, Sharifzad F, Taghikhani A \& Baharvand H 2019 Interaction between mesenchymal stromal cellderived extracellular vesicles and immune cells by distinct protein content. Journal of Cellular Physiology 234 8249-8258. (https://doi. org/10.1002/jcp.27669)

Martinowich K, Manji H \& Lu B 2007 New insights into BDNF function in depression and anxiety. Nature Neuroscience 10 1089-1093. (https:// doi.org/10.1038/nn1971)

Meister TA, Rimoldi SF, Soria R, Von Arx R, Messerli FH, Sartori C, Scherrer U \& Rexhaj E 2018 Association of assisted reproductive technologies with arterial hypertension during adolescence. Journal of the American College of Cardiology 72 1267-1274. (https://doi. org/10.1016/j.jacc.2018.06.060)

Mineur YS, Obayemi A, Wigestrand MB, Fote GM, Calarco CA, Li AM \& Picciotto MR 2013 Cholinergic signaling in the hippocampus regulates social stress resilience and anxiety- and depression-like behavior. PNAS 110 3573-3578. (https://doi.org/10.1073/pnas.1219731110)

Mossa A \& Manzini MC 2021 Molecular causes of sex-specific deficits in rodent models of neurodevelopmental disorders. Journal of Neuroscience Research 99 37-56. (https://doi.org/10.1002/jnr.24577)

Moulin TC, Covill LE, Itskov PM, Williams MJ \& Schioth HB 2021 Rodent and fly models in behavioral neuroscience: an evaluation of methodological advances, comparative research, and future perspectives. Neuroscience and Biobehavioral Reviews 120 1-12. (https://doi.org/10.1016/j.neubiorev.2020.11.014)

Nakajima K, Hida H, Shimano Y, Fujimoto I, Hashitani T, Kumazaki M, Sakurai T \& Nishino H 2001 GDNF is a major component of trophic activity in DA-depleted striatum for survival and neurite extension of
DAergic neurons. Brain Research 916 76-84. (https://doi.org/10.1016/ s0006-8993(01)02866-9)

Nedic Erjavec G, Sagud M, Nikolac Perkovic M, Svob Strac D, Konjevod M, Tudor L, Uzun S \& Pivac N 2021 Depression: biological markers and treatment. Progress in Neuro-Psychopharmacology and Biological Psychiatry 105 110139. (https://doi.org/10.1016/j.pnpbp.2020.110139)

Neis VB, Moretti M, Rosa PB, Dalsenter YO, Werle I, Platt N, Kaufmann FN, Rosado AF, Besen MH \& Rodrigues ALS 2020 The involvement of PI3K/ Akt/mTOR/GSK3beta signaling pathways in the antidepressant-like effect of AZD6765. Pharmacology, Biochemistry, and Behavior 198173020. (https://doi.org/10.1016/j.pbb.2020.173020)

Notaras M, Hill R \& Van Den Buuse M 2015 The BDNF gene Val66Met polymorphism as a modifier of psychiatric disorder susceptibility: progress and controversy. Molecular Psychiatry 20 916-930. (https://doi. org/10.1038/mp.2015.27)

Oyola MG \& Handa RJ 2017 Hypothalamic-pituitary-adrenal and hypothalamic-pituitary-gonadal axes: sex differences in regulation of stress responsivity. Stress 20 476-494. (https://doi.org/10.1080/102538 90.2017.1369523)

Palumbo S, Paterson C, Yang F, Hood VL \& Law AJ 2021 PKBbeta/AKT2 deficiency impacts brain mTOR signaling, prefrontal cortical physiology, hippocampal plasticity and select murine behaviors. Molecular Psychiatry 26 411-428. (https://doi.org/10.1038/s41380-020-00964-4)

Pentkowski NS, Rogge-Obando KK, Donaldson TN, Bouquin SJ \& Clark BJ 2021 Anxiety and Alzheimer's disease: behavioral analysis and neural basis in rodent models of Alzheimer's-related neuropathology. Neuroscience and Biobehavioral Reviews 127 647-658. (https://doi. org/10.1016/j.neubiorev.2021.05.005)

Pollak DD, Rey CE \& Monje FJ 2010 Rodent models in depression research: classical strategies and new directions. Annals of Medicine 42 252-264. (https://doi.org/10.3109/07853891003769957)

Prut L \& Belzung C 2003 The open field as a paradigm to measure the effects of drugs on anxiety-like behaviors: a review. European Journal of Pharmacology 463 3-33. (https://doi.org/10.1016/s00142999(03)01272-x)

Puzzo D, Lee L, Palmeri A, Calabrese G \& Arancio O 2014 Behavioral assays with mouse models of Alzheimer's disease: practical considerations and guidelines. Biochemical Pharmacology 88 450-467. (https://doi. org/10.1016/j.bcp.2014.01.011)

Qin N, Zhou Z, Zhao W, Zou K, Shi W, Yu C, Liu X, Dong Z, Mao Y, Liu X et al. 2021 Abnormal glucose metabolism in male mice offspring conceived by in vitro fertilization and frozen-thawed embryo transfer. Frontiers in Cell and Developmental Biology 9 637781. (https://doi. org/10.3389/fcell.2021.637781)

Ransome Y, Slopen N, Karlsson O \& Williams DR 2017 The association between alcohol abuse and neuroendocrine system dysregulation: race differences in a national sample. Brain, Behavior, and Immunity 66 313-321. (https://doi.org/10.1016/j.bbi.2017.07.154)

Rexhaj E, Pireva A, Paoloni-Giacobino A, Allemann Y, Cerny D, Dessen P, Sartori C, Scherrer U \& Rimoldi SF 2015 Prevention of vascular dysfunction and arterial hypertension in mice generated by assisted reproductive technologies by addition of melatonin to culture media. American Journal of Physiology: Heart and Circulatory Physiology 309 H1151-H1156. (https://doi.org/10.1152/ajpheart.00621.2014)

Salazar de Pablo G, Solmi M, Vaquerizo-Serrano J, Radua J, Passina A, Mosillo P, Correll CU, Borgwardt S, Galderisi S, Bechdolf A et al. 2021 Primary prevention of depression: an umbrella review of controlled interventions. Journal of Affective Disorders 294 957-970. (https://doi. org/10.1016/j.jad.2021.07.101)

Sampino S, Zacchini F, Swiergiel AH, Modlinski AJ, Loi P \& Ptak GE 2014 Effects of blastomere biopsy on post-natal growth and behavior in mice. Human Reproduction 29 1875-1883. (https://doi.org/10.1093/humrep/ deu145)

Sandin S, Nygren KG, Iliadou A, Hultman CM \& Reichenberg A 2013 Autism and mental retardation among offspring born after in vitro fertilization. JAMA $\mathbf{3 1 0}$ 75-84. (https://doi.org/10.1001/ jama.2013.7222)

Schenewerk AL, Ramirez Fí, Foote C, Ji T, Martinez-Lemus LA \& Rivera RM 2014 Effects of the use of assisted reproduction and high-caloric diet consumption on body weight and cardiovascular health of juvenile mouse offspring. Reproduction 147 111-123. (https://doi.org/10.1530/ REP-13-0354) 
Scott KA, Yamazaki Y, Yamamoto M, Lin Y, Melhorn SJ, Krause EG, Woods SC, Yanagimachi R, Sakai RR \& Tamashiro KL 2010 Glucose parameters are altered in mouse offspring produced by assisted reproductive technologies and somatic cell nuclear transfer. Biology of Reproduction 83 220-227. (https://doi.org/10.1095/biolreprod.109.082826)

Sharpe RM 2018 Of mice and men: long-term safety of assisted reproduction treatments. Human Reproduction 33 793-796. (https://doi.org/10.1093/ humrep/dey071)

Snyder JS, Soumier A, Brewer M, Pickel J \& Cameron HA 2011 Adult hippocampal neurogenesis buffers stress responses and depressive behaviour. Nature 476 458-461. (https://doi.org/10.1038/nature10287)

Sparling J, Ramey SL \& Ramey CT 2021 Mental health and social development effects of the abecedarian approach. International Journal of Environmental Research and Public Health 18 6997. (https://doi. org/10.3390/ijerph18136997)

Steptoe PC \& Edwards RG 1978 Birth AFTER the reimplantation of a human embryo. Lancet 213 366. (https://10.1016/s0140-6736(78)92957-4)

Steru L, Chermat R, Thierry B \& Simon P 1985 The tail suspension test: a new method for screening antidepressants in mice. Psychopharmacology 85 367-370. (https://doi.org/10.1007/BF00428203)

Strata F, Giritharan G, Sebastiano FD, Piane LD, Kao CN, Donjacour A \& Rinaudo P 2015 Behavior and brain gene expression changes in mice exposed to preimplantation and prenatal stress. Reproductive Sciences 22 23-30. (https://doi.org/10.1177/1933719114557900)

Strömberg B, Dahlquist G, Ericson A, Finnström $O$, Köster $M$ \& Stjernqvist K 2002 Neurological sequelae in children born after in-vitro fertilisation: a population-based study. Lancet 359 461-465. (https://doi. org/10.1016/S0140-6736(02)07674-2)

Su M, Soomro SH, Jie J \& Fu H 2021 Effects of the extracellular matrix on myelin development and regeneration in the central nervous system. Tissue and Cell 69 101444. (https://doi.org/10.1016/j. tice.2020.101444)

Sun J, Kong L, Wu F, Wei Y, Zhu Y, Yin Z, Deng X, Jiang X, Tang Y \& Wang F 2019 Decreased plasma glial cell line-derived neurotrophic factor level in major depressive disorder is associated with age and clinical severity. Journal of Affective Disorders 245 602-607. (https://doi.org/10.1016/j. jad.2018.11.068)

Sun J, Lu Y, Yang J, Song Z, Lu W \& Wang JH 2020 mRNA and microRNA profiles in the amygdala are relevant to susceptibility and resilience to psychological stress induced in mice. Journal of Molecular Neuroscience 70 1771-1796. (https://doi.org/10.1007/s12031-020-01570-3)

Thoenen H 1995 Neurotrophins and neuronal plasticity. Science 270 593-598. (https://doi.org/10.1126/science.270.5236.593)

Turkgeldi E, Yagmur H, Seyhan A, Urman B \& Ata B 2016 Short and long term outcomes of children conceived with assisted reproductive technology. European Journal of Obstetrics, Gynecology, and Reproductive Biology 207 129-136. (https://doi.org/10.1016/j.ejogrb.2016.10.010)

Unal G \& Canbeyli R 2019 Psychomotor retardation in depression: a critical measure of the forced swim test. Behavioural Brain Research 372 112047. (https://doi.org/10.1016/j.bbr.2019.112047)

Virtuoso A, De Luca C, Gargano F, Colangelo AM \& Papa M 2020 The spinal extracellular matrix modulates a multi-level protein net and epigenetic inducers following peripheral nerve injury. Neuroscience $\mathbf{4 5 1}$ 216-225. (https://doi.org/10.1016/j.neuroscience.2020.09.051)

von Bohlen Und Halbach O \& von Bohlen Und Halbach V 2018 BDNF effects on dendritic spine morphology and hippocampal function. Cell and Tissue Research 373 729-741. (https://doi.org/10.1007/s00441017-2782-x)

Vrooman LA \& Bartolomei MS 2017 Can assisted reproductive technologies cause adult-onset disease? Evidence from human and mouse. Reproductive Toxicology 68 72-84. (https://doi.org/10.1016/j. reprotox.2016.07.015)

Walf AA \& Frye CA 2007 The use of the elevated plus maze as an assay of anxiety-related behavior in rodents. Nature Protocols 2 322-328. (https://doi.org/10.1038/nprot.2007.44)

Wang Q, Zhang Y, Le F, Wang N, Zhang F, Luo Y, Lou Y, Hu M, Wang L, Thurston LM et al. 2018 Alteration in the expression of the reninangiotensin system in the myocardium of mice conceived by in vitro fertilization. Biology of Reproduction 99 1276-1288. (https://doi. org/10.1093/biolre/ioy158)

Watkins AJ, Platt D, Papenbrock T, Wilkins A, Eckert J, Kwong WY, Osmond C, Hanson M \& Fleming TP 2007 Mouse embryo culture induces changes in postnatal phenotype including raised systolic blood pressure. PNAS 104 5449-5454. (https://doi.org/10.1073/pnas.0610317104)

Werner-Seidler A, Perry Y, Calear AL, Newby JM \& Christensen H 2017 School-based depression and anxiety prevention programs for young people: a systematic review and meta-analysis. Clinical Psychology Review 51 30-47. (https://doi.org/10.1016/j.cpr.2016.10.005)

Winett L, Wallack L, Richardson D, Boone-Heinonen J \& Messer L 2016 A framework to address challenges in communicating the developmental origins of health and disease. Current Environmental Health Reports 3 169-177. (https://doi.org/10.1007/s40572-016-0102-3)

Wu Y, Lv Z, Yang Y, Dong G, Yu Y, Cui Y, Tong M, Wang L, Zhou Z, Zhu H et al. 2014 Blastomere biopsy influences epigenetic reprogramming during early embryo development, which impacts neural development and function in resulting mice. Cellular and Molecular Life Sciences $\mathbf{7 1}$ 1761-1774. (https://doi.org/10.1007/s00018-013-1466-2)

Yankelevitch-Yahav R, Franko M, Huly A \& Doron R 2015 The forced swim test as a model of depressive-like behavior. Journal of Visualized Experiments 97 52587. (https://doi.org/10.3791/52587)

Yu Y, Wu J, Fan Y, Lv Z, Guo X, Zhao C, Zhou R, Zhang Z, Wang F, Xiao M et al. 2009 Evaluation of blastomere biopsy using a mouse model indicates the potential high risk of neurodegenerative disorders in the offspring. Molecular and Cellular Proteomics 8 1490-1500. (https://doi. org/10.1074/mcp.M800273-MCP200)

Yu Y, Zhao C, Lv Z, Chen W, Tong M, Guo X, Wang L, Liu J, Zhou Z, Zhu H et al. 2011 Microinjection manipulation resulted in the increased apoptosis of spermatocytes in testes from intracytoplasmic sperm injection (ICSI) derived mice. PLoS ONE 6 e22172. (https://doi. org/10.1371/journal.pone.0022172)

Zheng MM, Cao HR, Zhang WY, Yan PP, Xu JY, Zhao HL, Zhu F, Zhang JJ, Li Y \& Zhu H 2018 Abnormal gene methylation during embryonic development after preimplantation genetic testing increases risk of liverderived insulin resistance. Annals of the New York Academy of Sciences 1425 70-81. (https://doi.org/10.1111/nyas.13700)

Zhu JL, Basso O, Obel C, Hvidtjorn D \& Olsen J 2009 Infertility, infertility treatment and psychomotor development: the Danish National Birth Cohort. Paediatric and Perinatal Epidemiology 23 98-106. (https://doi. org/10.1111/j.1365-3016.2008.00989.x)

Received 20 April 2021

First decision 25 May 2021

Revised manuscript received 21 September 2021

Accepted 4 October 2021 